\title{
The effect of aggregations on bimodal kaolinite soils
}

\author{
Vinícius de Oliveira Kühn ${ }^{1,2, *}$, Manoel Porfírio Cordão Neto ${ }^{2}$, Bruna de Carvalho Faria Lima Lopes ${ }^{3}$ \\ ${ }^{1}$ Universidade Federal do Oeste da Bahia, Centro das Ciências Exatas e Tecnologias, 47808-021, Barreiras, Brazil \\ ${ }^{2}$ Universidade de Brasília, Faculdade de Tecnologia, 70910-900 Brasília, Brazil \\ ${ }^{3}$ University of Strathclyde, Faculty of Engineering, G1 1XJ, Glasgow, UK
}

\begin{abstract}
Residual bimodal soils present great complexity of hydraulic and mechanical behaviour, due to the presence of aggregations, mineralogy and complex structures. These soils often present a clear bimodality with a wide difference between the size of intra-aggregate and inter-aggregate pores, of 2 to 3 orders of magnitudes. The objective of this work is to produce a soil with bimodal characteristics using Kaolin Clay, in order to eliminate possible mineralogical, particle size and structural variables, since the clay mineral present in this material is mainly Kaolinite. Analyses of the effect of stable aggregations on soil structural behaviour were carried out by means of soil water retention curve (SWRC). For this, a new methodology was developed for the production of stable aggregations, which were used to compose new bimodal soils. Then, a series of comparisons between the SWRC of the soil with and without aggregation were carried out. Results showed that the presence of aggregations had a direct impact on soil plasticity, particle size classification and compaction curve.
\end{abstract}

\section{Introduction}

Soils with dual-porosity, or bimodal soils, can be understood as soils that present two distinct dominant pore sizes, which may be naturally occurring or a result of compaction.

Clayey or silty soils compacted on the dry side of the compaction curve display a bimodal pore structure while soils compacted on the wet side of the compaction curve or reconstituted slurries present unimodal pore structures [1].

Many tropical residual soils have naturally bimodal pore structures. In these cases, it is common to observe the presence of aggregations, forming inter-aggregate pores, and the existence of intra-aggregate pores, formed between aggregations. This is the case of the porous clay soil of Brasilia, Brazil, which often exhibits collapsing behaviour. Many studies carried out in this soil material have shown that the differences in size of the dominant intra-aggregate and inter-aggregate pores can reach between 2 and 3 orders of magnitudes [2 -4]. Brasilia soil also displays great mineralogical variability, which makes it difficult to understand how each mineral plays a role in the overall behaviour of the soil.

Moreover, it is still not clear amongst geotechnists the role and influence of aggregations in the hydromechanical behaviour of soils. Similarly, the part aggregations play in the most fundamental aspects, such as Atterberg limits and compaction curve, is also not fully established.

The objective of this work is to produce a bimodal soil with two distinct and stable dominant pore sizes, where the kaolinite clay mineral predominantly overwhelms the presence of any other clay mineral, thus eliminating any mineralogical variability. In order to assess the bimodal soil created, changes in the soil water retention curve, particle size, Atterberg limits and compaction curve were also evaluated.

\section{Background}

\subsection{Mineralogy of clays and interparticle forces}

In this sense, in order to understand soils with great mineralogical variability and complex structures it is fundamental to start by studying the behaviour of soils with simpler structures and that forms the basis for the complex soil, as well as the forces acting at a particle level.

The mineralogical constitution of soils is a primary factor controlling the size, shape and properties of solid particles. The mineralogy of clays can be divided into $1: 1$ (1 octahedral aluminium and 1 tetrahedral silica) and 2:1 (1 octahedral aluminium and 2 tetrahedral silica) structures. Of the minerals $1: 1$ are Kaolinite and Halloysite, while the minerals 2:1 correspond to Smectites, Illites, Vermiculite, Chlorite, among others. In addition to the number of layers and packaging the clay minerals differ by the presence of water and ions in their structures [5].

Like the minerals involved, the forces that occur between the particles are important for the compression of the soil structure, since the structure is a combination of soil fabric and interparticle forces.

${ }^{*}$ Corresponding author: vinicius.kuhn@ $@$ ufob.edu.br 
The interparticle forces can be divided into 3 categories: 1. Forces due to external loading: these forces are transmitted through the particles by contact due to the application of external loads; 2. Forces at particle level: including particle weight, flowability and hydrodynamic forces. They can occur even without the presence of solid skeleton; 3. Contact Forces: these include electrical forces, capillary forces when the ground becomes unsaturated and reactive forces to the cementation [6].

With the application of external loads, normal and tangential forces occur in the contacts between the particles, which experience these forces in different ways depending on their relative position in relation to the neighbouring particle. The evolution and distribution of the forces in the solid skeletal has a direct influence on the stress-strain behaviour, volume variation and soil strength [5].

Interparticular forces may be of repulsion or attraction. It is accepted in colloid science that the most important physicochemical forces are van der Waals forces of attraction and repulsive double layer forces.

The total interaction between two particles, including Van der Waals forces and double layer forces, is explained by the DLVO (Derjaguin, Landau, Verwey and Overbeek) theory [7].

The double-layer repulsion forces are sensitive to salt and $\mathrm{pH}$ concentrations, unlike Van der Waals forces that are insensitive to these variations. In addition, Van der Waals' attractive forces always exceed double layer forces for very small distances between particles, whereas within the double layer interaction energy remains finite or increases very slowly [8].

\subsection{Structural behaviour of bimodal soils}

The so-called bimodal soils have two distinct dominant pore sizes, unlike soils with only one pore size, which are called unimodal.

It is important to emphasize that the definition of dualporosity, or bimodality of pores, must be relativized. That is, highly weathered soils have a great size difference between the dominant intra-aggregate and inter-aggregate porosity, of two to three orders of magnitude; therefore, they are clearly bimodal soils. However, other soils, also considered bimodal, present a narrow difference between the size of the dominant intra-aggregate and interaggregate pores.

Thom et al. [9] used compacted Kaolin clay in the dry side of the compaction curve to evaluate the structure after wetting. A triaxial apparatus was used in which samples were compressed isotropically at 400 and $800 \mathrm{kPa}$ and then saturated. During the saturation process there was an increase in total volume, meanwhile a decrease of the intra-aggregate pores and increase of the inter-aggregate pores was observed in the pore size distribution (PSD).

Tarantino and De Col [10] evaluated the behaviour of Kaolin clay during compression with suction monitoring during loading and PSD analysis after loading. The PSDs presented bimodal behaviour that depended on moisture content. As the moisture content decreased the pore mode sizes did not change, but the inter-aggregate porosity increased and the intra-aggregate porosity decreased. At lower moisture contents the intra-aggregate size disappeared, becoming unimodal.

Still on the discussions of the results of Tarantino and De Col [10], the authors [11] claimed that the bimodal pore size distribution is linked to aggregates formed during the wetting and sieving on the sample's preparation phase. That is, samples with higher moisture contents tend to form aggregates and therefore bimodal PSD, which does not occur in samples with lower moisture content.

Bagherieh et al. [12] and Foong et al. [13] showed similar sample preparation procedures, wherein the Kaolin material is moistened and sieved to obtain granules. These procedures were used for forming the inter-aggregate structure of statically compacted samples.

\section{Materials and methods}

The Kaolin clay used in the research, presents liquid limit, $\mathrm{w}_{\mathrm{L}}$, of $54.6 \%$, plasticity index, $\mathrm{I}_{\mathrm{P}}$, of $16.1 \%$ and specific gravity, $\mathrm{G}_{\mathrm{s}}$, is 2.54 . The particle size distribution is formed by $55 \%$ of clay and $45 \%$ of silt, which leads to classify the soil as Highly Plastic Silt (MH) according to the Unified Soil Classification System (USCS). Compaction tests were performed using normal and Modified Proctor energy.

\subsection{Primary compaction}

In order to obtain aggregations, Kaolin clay material was moistened under different conditions and compacted with different energies in order to obtain a stable sample when immersed in water, i.e., the aggregations did not crumble when samples were immersed in water. California Bearing Ratio (CBR) and concrete press were used for the tests. The evaluation was done with a Crumb test.

All samples were prepared and left to equilibrate for at least 24 hours, they were then compacted at a speed of $1.2 \mathrm{~mm} / \mathrm{min}$, until the desired stress was reached, then the target stress was maintained on the sample for additional $30 \mathrm{~min}$ to ensure homogeneity.

The aim of the primary compaction is to apply a stress level to the material that is able to reduce the distance between the kaolinite particles favouring the Van der Walls attractive forces over the repulsive double layer forces.

The compacted stable sample has stress history of 100 MPa, $80 \%$ degree of saturation and 0.32 void index (Table 1). These samples were used to obtain the stable aggregations that were used in the next phase of the methodology and are called parent sample of aggregation (PSA).

\subsection{Secondary compaction}

The material obtained in the previous section was ovendried and crushed. Then it was mixed with the original pure Kaolin clay in a way that $57.8 \%$ of the resulted material passed through the $2 \mathrm{~mm}$ sieve and $37.5 \%$ passed through the $0.075 \mathrm{~mm}$ sieve, this material is herein 
referred to as Bimodal Kaolin. The decision-making process of the selected particle size distribution was defined based on the typical particle size distribution of the Brasilia soil [2].

In order to obtain the compaction curve of this new material the Mini Proctor compaction test [14] was carried out. The choice of the MiniProctor test over the ordinary Proctor test was due to the limited amount of material available.

From the resulting material two samples were created: Firstly, a sample, herein referred to as High Energy Bimodal Sample $(\mathrm{HBi})$ compacted statically at high energy (Table 1). The second sample was statically compacted near the dry side of the compaction curve of this new material, herein referred to as Bimodal Sample (Bi). Table 1 summarises the origin and compaction characteristics of the samples produced in this study.

For sake of comparison, an additional sample made of pure Kaolin only was compacted in the same condition as $B i$. This sample is herein referred to as Kaolin Sample $(K S)$. It is worth stressing that $K S$ and $B i$ samples have identical compaction characteristics, as shown in Table 1. Comparisons between these samples $(K S, B i$ and $H B i)$ are legit since this is a customary geotechnical approach of investigating differences in soils that although have the same origin present different behaviour (e.g. hydromechanical) due to their distinct formation process.

Here, it has been acknowledged that, as noticed by other authors [9, 10, 12-13], aggregates are formed on Kaolin samples during the preparation process for compaction, however the nature of these aggregations are different from the stability nature of the aggregates formed on the procedure described in this paper. This difference will be more evident once results of particle size distribution are presented in the results and discussions section.

Table 1. Origin and compaction characteristics of samples produced in this study

\begin{tabular}{ccccc}
\hline Name & Origin & $\begin{array}{c}\mathbf{w} \\
(\mathbf{\%})\end{array}$ & $\begin{array}{c}\boldsymbol{\gamma}_{\mathbf{d}} \\
\left(\mathbf{k N} / \mathbf{m}^{\mathbf{3}}\right)\end{array}$ & $\mathbf{e}$ \\
\hline $\mathrm{KS}$ & $\begin{array}{c}\text { Pure Kaolin } \\
\text { Clay }\end{array}$ & 26.9 & 12.3 & 1.01 \\
$\mathrm{Bi}$ & $\begin{array}{c}\text { PSA and Pure } \\
\text { Kaolin Clay }\end{array}$ & 26.9 & 12.3 & 1.00 \\
$\mathrm{HBi}$ & $\begin{array}{c}\text { PSA and Pure } \\
\text { Kaolin Clay }\end{array}$ & 25.1 & 14.1 & 0.76 \\
& $\begin{array}{c}\text { Pure Kaolin } \\
\text { Clay }\end{array}$ & 10.0 & 18.8 & 0.32 \\
\hline
\end{tabular}

\subsection{Soil water retention curve}

Tests were carried out to determine the soil water retention curve (SWRC) on samples obtained through the secondary compaction and also on the PSA.

Axis translation tests were used for suctions up to 500 $\mathrm{kPa}$ and dewpoint psychrometer (WP4C) for suctions above $500 \mathrm{kPa}$. The technique of axis translation imposes matric suctions and WP4C determines total suctions, but in the case under study, an agreement between matric and total suctions between 200 and $500 \mathrm{kPa}$ was observed, which allows the determination of the SWRC in terms of matric suction.

All samples were initially moistened by capillarity and then the water retention curve was determined in the drying path.

\section{Results and discussions}

\subsection{Compaction, Atterberg Limits and Particle size distribution}

Fig. 1 shows the compaction curves of the Kaolin clay and the Bimodal Kaolin material, as well as the compaction characteristics of the samples presented in Table 1 and compaction results of the stability tests performed in the primary compaction stage. The circular points in the graph represent the samples that undergo the crumb test. Red circular points are the stable samples while white circular points represent the samples that failed the crumble test by disaggregating when immersed in water.

It can be observed the agreement between the compaction curve of Kaolin with normal energy and the Mini Proctor test, highlighting the validity of the Mini Proctor test. The presence of stable aggregations on the Bimodal Kaolin (originated from the PSA) generates an expressive change in the compaction curve, with reduction of the optimal water content and increase of the specific dry weight.

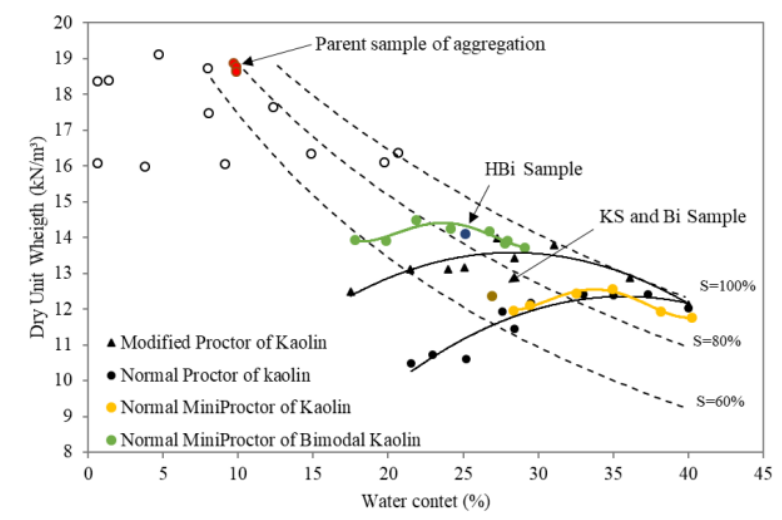

Fig. 1. Compaction curves and Stability tests.

With respect to the Atterberg Limits, the Bimodal Kaolin showed a drop in the liquid limit, from 54.6 to $39.4 \%$ (Fig. 2), and Plasticity Limit, from 38.5 to $32.7 \%$, decreasing its plasticity index, from 16.1 to $6.7 \%$, consequently changing its classification from $\mathrm{MH}$ to Low Plasticity Silt (ML) (Fig. 3). Although the materials presented mineralogy containing only kaolinite clay minerals, the presence of stable aggregations resulted in a decrease of the specific surface of the particles, thus reducing its plasticity. 


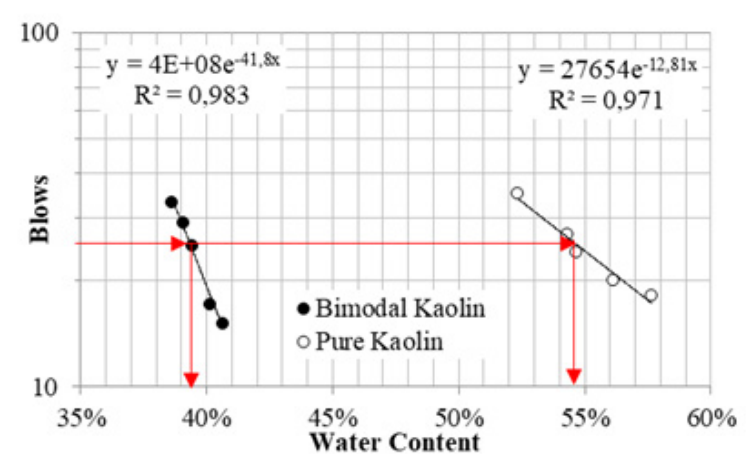

Fig. 2. Liquid limit of pure Kaolin and Bimodal Kaolin.

Wang and Siu [15] observed that the liquid limit of Kaolin Clay increases as the $\mathrm{pH}$ decreases and the structure becomes more flocculated; and the plasticity index increases as the $\mathrm{pH}$ decreases. Sridharan et al. [16] and Sridharan and Prakash [17] also made explanations attributing the changes in Atterberg limits to changes in the soil structure. Fearon and Coop [18] observed an increase in the values of liquid limit and plasticity index with reconstitution of the sample and also with the energy and process of reconstitution.

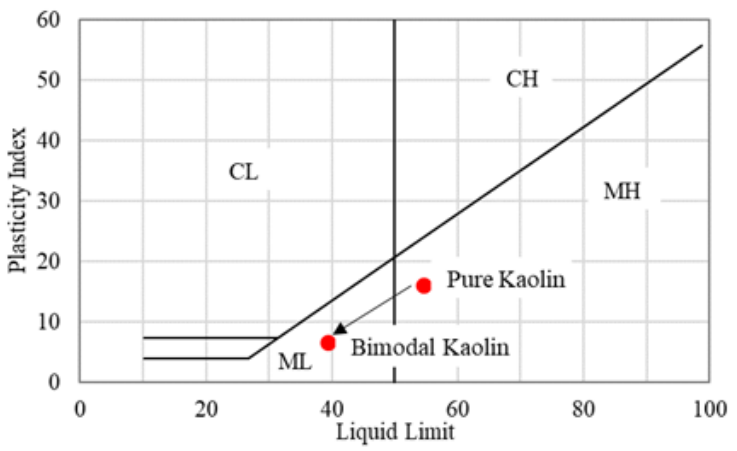

Fig. 3. Effect of stable aggregation on classification.

The particle size tests were performed with and without dispersant on the Kaolin clay and Bimodal Kaolin (Fig. 4). The particle size distribution curve of the pure Kaolin without dispersant presented zero percentage of clay size particles and a plateau is reached in a diameter of $0.004 \mathrm{~mm}$. This factor can be attributed to the effect of agglomeration of the clay particles due to electrostatic forces when immersed in aqueous medium without chemical dispersing agent.

It is observed a great difference between the particle size distribution between the Bimodal Kaolin samples, with and without dispersant. The results show that the stable aggregations produced are indeed stable in water and that the dispersant was able to eliminate the majority of them. However, when the Bimodal Kaolin sample with dispersant was compared with the pure Kaolin sample with dispersant, it was observed that some of the stable aggregations created in the Bimodal Kaolin sample were not completely wiped out.

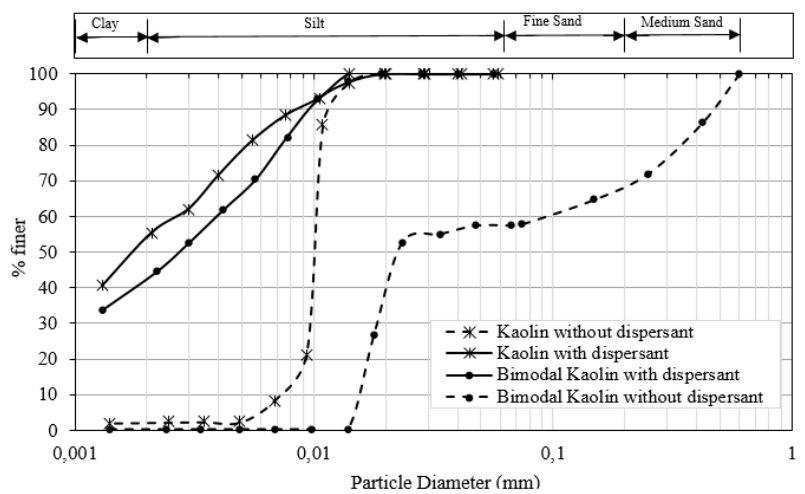

Fig. 4. Particle size curve of Kaolin and Bimodal Kaolin with and without dispersant.

\subsection{Soil water retention curve}

Fig. 5 and Fig. 6 show the SWRC of the samples tested. The curves are presented using the water index $\left(\mathrm{e}_{\mathrm{w}}\right.$ $=\mathrm{V}_{\mathrm{w}} / \mathrm{V}_{\mathrm{s}}$, where $\mathrm{V}_{\mathrm{w}}$ represents volume of water and $\mathrm{V}_{\mathrm{s}}$ represents volume of solids) and the fittings using the correlations proposed by Durner [19], which extends Van Genutchen [20] equation for bimodal and multimodal soils.

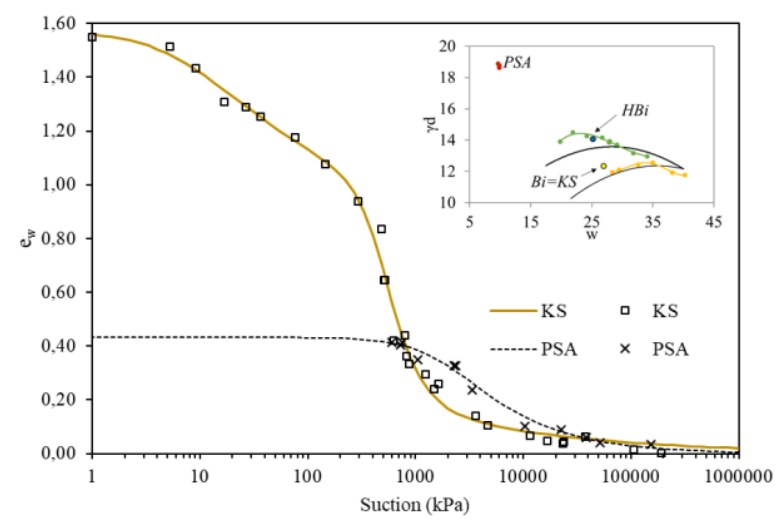

Fig. 5. Soil water retention curve of PSA and KS Samples

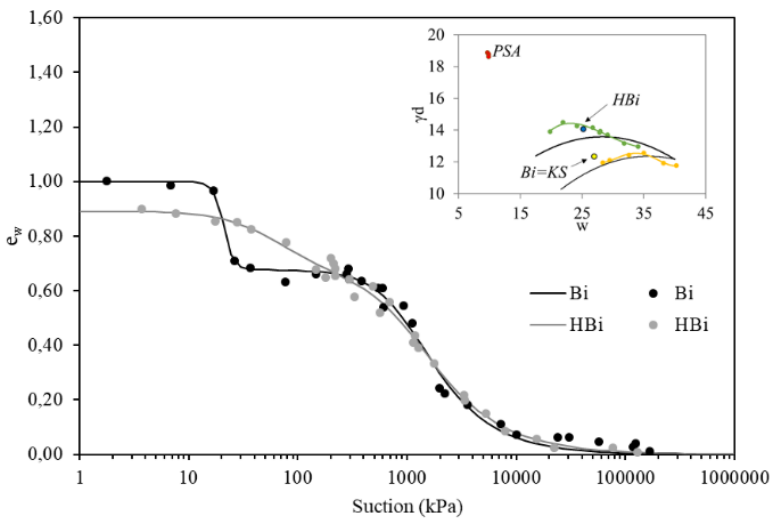

Fig. 6. Soil water retention curve of HBi and Bi Samples.

It can be noted that the methodology used was adequate for the creation of bimodal soils with different pore size. In particular, as shown in Fig. 5 and Fig. 6, a relevant difference between $K S$ and $B i$ samples is observed. Although both samples were compacted in the same conditions, the presence of stable aggregations in 
the $B i$ sample was determinant for the creation of a bimodal structure. For the $B i$ sample water starts to drain out of the intra-aggregate pores with a suction of $20 \mathrm{kPa}$ and from the inter-aggregate pores with a suction $200 \mathrm{kPa}$, which represents two orders of magnitude between the two porosities.

In the $K S$ sample it is not possible to clearly identify the level in which the draining within the intra-aggregate pores ends and the draining amongst the inter-aggregate pores begins.

The increase in energy for the production of the $H B i$ sample closed part of the intra-aggregate pores of the sample. Finally, the PSA Sample has a clear unimodal curve.

It is important to emphasize that the $K S$ sample presented high expansion when compared to the other samples during the saturation process. The $K S$ sample showed volumetric deformation at saturation of $17 \%$. The $B i$ sample presented deformation of $4.48 \%$, significantly lower than the value registered by $K S$, even though both were compacted in the same conditions. What corroborates with this observation is the decrease in plasticity of the $B i$ sample due to the presence of stable aggregations and decrease of its specific surface. The $H B i$ sample showed expansion of $3.71 \%$. The compacted sample PSA for formation of stable aggregation showed expansion of $13.51 \%$.

\section{Conclusion}

This paper presented a new methodology to analyse soils with aggregations and distribution of bimodal pores. It was observed that the distinct behaviour of the soil with and without stable aggregations is related to the change in the specific surface of the particles, decrease of plasticity index and decrease in the expansivity of the samples.

A bimodal pore distribution of the samples was observed through the SWRC. However, the increase in energy tends to decrease the difference in size between intra-aggregate and inter-aggregate pores. In the tests carried out, a decrease of intra-aggregate pores was observed with increased loading and little change in interaggregate pores.

This study contributes to the study of clayey bimodal soils, with low mineralogical complexity, considering that the material used presents only Kaolinite clay mineral. It is important to note that the dual-porosity of the soil presents great difference in size between the dominant intra-aggregate and inter-aggregate pores, as this is typical of highly weathered residual soils. Therefore, future studies could draw a parallel between the behaviour of soils produced with this methodology and natural bimodal soils. This characteristic could be extremely useful for differentiating the effect of the soil microstructure on the macroscopic behaviour of soils

The authors would also like to acknowledge the Brazilian research council, the National Council for Scientific and Technological Development $(\mathrm{CNPq})$ for providing the funds for the acquisition of equipment used in this research.

\section{References}

1. M. Pedrotti, A. Tarantino. Inter-aggregate structural interpretation of compression behaviour of compacted Kaolin clay. In: Unsaturated Soils. CRC Press, Leiden, 739-745. (2014).

2. I. F. C. Otalvaro. Comportamento Hidromecânico de um Solo Tropical Compactado. Programa de PósGraduação em Geotecnia. Universidade de Brasília. 122. (2013)

3. C. R. Borges. Estudo inter-aggregateestrutural do comportamento hidromecânico do solo de BrasíliaDF. Programa de Pós-Graduação em Geotecnia. Universidade de Brasília. 111. (2014)

4. B. C. F. L. Lopes. Inter-aggregate structural based approach to the modelling of clays and transitional soils behaviour. Programa de Pós-Graduação em Geotecnia. Universidade de Brasília. 133. (2016)

5. J. K. Mitchell, K. Soga, K. Fundamentals of Soil Behavior. John Wiley \& Sons, INC, 558. (2005).

6. J. C. Santamarina. Soil Behaviour at the Interaggregate scale: Particle Forces. Proc. Symp. Soil Behaviour and Soft Ground Construction, MIT. 132. (2001)

7. E. J. W. Verwey, J. TH. G. Overbeek. Theory of the stability of Lyophobic colloids: the interaction of soil particles having and electric double layer. Elsevier. 205. (1948).

8. J. N. Israelachvili. Intermolecular and Surface Forces. Elsevier Inc. 706p. (2011).

9. R. Thom, R. Sivakumar, V, Sivakumar, E. J. Murray, P. Mackinnon. Pore size distribution of unsaturated compacted Kaolin: the initial states and final states following saturation. Technical note. Géotechnique, 57(5), 469-474. (2007).

10. A. Tarantino, E. De Col. Compaction behaviour of clay. Géotechnique. 58(3), 199-213. (2008)

11. A. Tarantino, E. De Col. Compaction behaviour of clay - Discussion. Géotechnique, 59(1), 75-77. (2009).

12. A. R. Bagherieh, N. Khalili, G. Habibagahi, A. Ghahramani. Drying response and effective stress in a dual-porosity aggregated soil. Engineering Geology, 105 (1-2), 44-50. (2009)

13. L. K. Foong, N. A. Rahman, M. Z. Ramli. A laboratory study of deformable double-porosity soil with distinct / (various) moisture content under vibration effect. Malaysian Journal of Civil Engineering. 28(3), 207-222. (2016).

14. D. F. Villibor, J. S. Nogami. Pavimentos Econômicos: tecnologia do uso dos solos finos lateríticos. Arte \& Ciência. 292. (2009).

15. Y. H. Wang, W. K. Siu. Structure characteristics and mechanical properties of kaolinite soils. I. Surface charges and structural characterizations. Canadian Geotechnical. Journal, 43(6), 587-600. (2006). 
16. A. Sridharan, S. M. Rao, N. S. Murthy. Liquid Limit of kaolinitic Soils. Géotechnique, 38(2), 191-198. (1988).

17. A. Sridharan, K. Prakash. Characteristic water contents for a fine-grained soil-water system. Géotechnique, 48(3), 337-346. (1998).

18. R. E. Fearon, M. R. Coop. Reconstitution: what makes an appropriate reference material? Géotechnique, 50(4), 471-477. (2000).

19. W. Durner. Hydraulic conductivity estimation for soils with heterogeneous pore structure. Water Resources Research, 30, 211-223. (1994)

20. M. Van Genutchen. A closed form equation for predicting the hydraulic conductivity of unsaturated. Soil Science Society of America Journal, 44, 892898 (1980). 